\title{
Measurement and Control of Dissolved Carbon Dioxide in Mammalian Cell Culture Processes Using an in Situ Fiber Optic Chemical Sensor
}

\author{
Robert N. Pattison,* J anani Swamy, Brett Mendenhall, Chris Hwang, and \\ Bert T. Frohlich ${ }^{\dagger}$
}

Genzyme Corporation, 500 Soldiers Field Road, Allston, Massachusetts 02134

\begin{abstract}
At high viable cell concentrations in large-scale mammalian cell culture processes, the accumulation of dissolved carbon dioxide $\left(\mathrm{dCO}_{2}\right.$, typically quantified as an equilibrium gas-phase concentration) becomes problematic as a result of low $\mathrm{CO}_{2}$ removal rates at reduced surface-to-volume ratios. High $\mathrm{dCO}_{2}$ concentrations have previously been shown to inhibit cell growth and product formation in mammalian cells and to al ter the glycosylation pattern of recombinant proteins. Therefore, reliable monitoring and control of $\mathrm{dCO}_{2}$ are important for successful large-scale operation. Off-line measurements by instruments such as blood gas analyzers (BGA) are constrained by the low frequency of data collection and cannot be used for on-line control. In a preliminary evaluation of the YSI 8500 in situ sensor, a response time ( $\left.\mathrm{t}_{90 \%}\right)$ of $6 \mathrm{~min}$, sensitivity of $0.5 \% \mathrm{CO}_{2}(3.6 \mathrm{mmHg})$, and linearity of measurement $\left(\mathrm{R}^{2}\right.$ $=0.9997)$ between the equivalent gas-phase partial pressure of $0-180 \mathrm{mmHg}(0 \%$ and $25 \% \mathrm{CO}_{2}$ ) were establ ished. Measurements were found to be unaffected by culture $\mathrm{pH}$ and typical mammalian cell culture concentrations of glucose, glutamine, glutamate, lactate, and ammonium. The sensor withstood repeated sterilization and cleaning cycles. The reliability of this sensor was demonstrated in microcarrier-based Chinese hamster ovary (CHO) cell perfusion cultures at reactor scales of 30, 40, 340, and $2000 \mathrm{~L}$ and was successfully implemented in a $\mathrm{dCO}_{2}$ control strategy using $\mathrm{N}_{2}$ sparging.
\end{abstract}

\section{Introduction}

The detrimental effects of elevated dissolved carbon dioxide $\left(\mathrm{dCO}_{2}\right)$ concentrations (typically quantified as equilibrium gas-phase concentrations) on mammalian cell cultures are well documented (1-6). $\mathrm{CO}_{2}$ is a nonpolar molecule, which can diffuse across the cell membrane and lower the intracellular pH (7), thereby affecting the activity of intracellular enzymes and altering cellular metabolism $(8,9)$.

$\mathrm{High} \mathrm{dCO}_{2}$ has been shown to inhibit cell growth, nutrient utilization, and product formation and in some cases to alter protein glycosylation. Physiological $\mathrm{dCO}_{2}$ in mammalian cells is roughly equivalent to a partial pressure $\left(\mathrm{pCO}_{2}\right)$ of $50-70 \mathrm{mmHg}$ at $37^{\circ} \mathrm{C}$. Drapeau et al. (1) found that cell growth and specific M-CSF production rates in a $\mathrm{CHO}$ cell culture decreased by $\sim 40 \%$ when the $\mathrm{pCO}_{2}$ was increased from 53 to $165 \mathrm{mmHg}$. Gray et al. (3) observed a progressive inhibition of cell growth and product formation above a $\mathrm{pCO}_{2}$ of $76 \mathrm{mmHg}$, in a $\mathrm{CHO}$ cell perfusion culture, with a $70 \%$ decrease in specific production rates at a $\mathrm{pCO}_{2}$ of $148 \mathrm{mmHg}$. They attempted stripping $\mathrm{CO}_{2}$, as a means of controlling $\mathrm{dCO}_{2}$, by increasing the bubble size of the sparged oxygen gas. This strategy was constrained because of the difficulty in balancing $\mathrm{O}_{2}$ supply and $\mathrm{CO}_{2}$ removal. Taticek et al .

\footnotetext{
* Email: robert.pattison@genzyme.com.

† Current Affiliation: Advanced Life Science Products, Corning Incorporated, Sullivan Park Research Center, SP AR 02 1, Corning, NY 14831.
}

(6) reported that specific protein production, glucose and glutamine consumption, and lactate production rates of a baby hamster kidney (BHK) cell culture all decreased by $\sim 40 \%$ as the culture $\mathrm{pCO}_{2}$ was increased from 130 to $280 \mathrm{mmHg}$. Kimura and Miller (10) found that the proportion of sialic acids containing $\mathrm{N}$-glycolylneuraminic acid decreased from $2.3-4.0 \%$ at a $\mathrm{pCO}_{2}$ of $36 \mathrm{mmHg}$ to $1.5-2.2 \%$ at a $\mathrm{pCO}_{2}$ of $250 \mathrm{mmHg}$. We have observed that elevated $\mathrm{dCO}_{2}$ concentrations can decrease product formation rates in microcarrier-based $\mathrm{CHO}$ cell perfusion cultures (results not shown).

To control pH, some mammalian cell culture processes employ the addition of base (e.g., $\mathrm{NaOH})$, which can compound the detrimental effects of elevated $\mathrm{dCO}_{2}$. Kimura and Miller (4) found that the growth rate of a $\mathrm{CHO}$ cell line, compared to the control at a $\mathrm{pCO}_{2}$ of 36 $\mathrm{mmHg}$ and an osmolality of $310 \mathrm{mOsm} / \mathrm{kg}$, decreased by $30 \%$ with an increase in $\mathrm{pCO}_{2}$ to $250 \mathrm{mmH} \mathrm{g}$. A concurrent increase in osmolality to $376 \mathrm{mOsm} / \mathrm{kg}$ decreased the growth rate by $45 \%$. In another study, the growth rate of a hybridoma cell line decreased by $40-50 \%$ when the $\mathrm{pCO}_{2}$ was increased from 36 to $195 \mathrm{mmHg}$ at a constant osmolality of $361 \mathrm{mOsm} / \mathrm{kg}(5)$. A concurrent increase in osmolality to $415 \mathrm{mOsm} / \mathrm{kg}$ decreased the growth rate by $63 \%$. There was a 31 -fold increase in cell death rate at a $\mathrm{pCO}_{2}$ of $250 \mathrm{mmHg}$ and an osmolality of $401 \mathrm{mOsm} / \mathrm{kg}$.

There is a need to accurately monitor and control $\mathrm{dCO}_{2}$ concentrations in mammalian cell culture processes. Offline sensors are limited by the low frequency of data 
collection and biases introduced by sample handling and are difficult to use for continuous control. For these reasons, attempts have been made to develop in situ $\mathrm{dCO}_{2}$ sensors.

Severinghaus and Bradley (11) developed the first in situ $\mathrm{dCO}_{2}$ sensor by using a gas-permeable membrane to separate a bicarbonate buffer from the analyte solution. When $\mathrm{CO}_{2}$ diffused across the membrane, a glass electrode measured the resulting $\mathrm{pH}$ change. The $\mathrm{pH}$ reading was converted to a $\mathrm{dCO}_{2}$ output based on the chemical equilibrium:

$$
\mathrm{CO}_{2}+\mathrm{H}_{2} \mathrm{O} \Leftrightarrow \mathrm{H}_{2} \mathrm{CO}_{3} \Leftrightarrow \mathrm{H}^{+}+\mathrm{HCO}_{3}{ }^{-}
$$

where

$$
K=\frac{\left[\mathrm{H}^{+}\right]\left[\mathrm{HCO}_{3}^{-}\right]}{\left[\mathrm{CO}_{2}\right]\left[\mathrm{H}_{2} \mathrm{O}\right]}
$$

The equilibrium constant, $\mathrm{K}$, is constant at a given temperature. Since the concentrations of $\mathrm{HCO}_{3}{ }^{-}$and $\mathrm{H}_{2} \mathrm{O}$ are significantly higher than those of $\mathrm{H}^{+}$and $\mathrm{CO}_{2}$, the concentration of $\mathrm{CO}_{2}$ is proportional to the concentration of $\mathrm{H}^{+}(\mathrm{pH})$ for a constant temperature.

A sterilizable version of this sensor was constructed by Puhar et al. (12) for in situ use in fermentations. Shoda and I shikawa (13) found that the internal bicarbonate buffer had to be replaced every 2 weeks and the probe itself, every 6 months, to ensure adequate measurement accuracy.

We evaluated a $\mathrm{dCO}_{2}$ sensor based on this technology from Phoenix Electrode Corporation. Although the sensor response was adequate, we were uncomfortable with this probe for long-term use. A stainless steel plug was required to support the membrane during the steam-inplace process (SIP) and was then replaced with the nonsterile probe and electrolyte solution after the SIP. The inability of the electrode to be sterilized posed a potential contamination risk since sterility depended solely on the integrity of the membrane.

We also evaluated an infrared technology using attenuated total reflectance. The ReactI R 1000 midrange infrared (Mid-IR) sensor from Applied Systems, Inc. (ASI) had adequate response and sensitivity to $\mathrm{dCO}_{2}$. The advantages of this technology were its robust construction and simultaneous in situ measurements of glucose, lactate, glutamine, glutamate, and ammonia, in addition to $\mathrm{dCO}_{2}$. However, the labor-intensive calibration, high purchase cost, and the need for liquid $\mathrm{N}_{2}$ cooling of the detector for adequate sensitivity made the implementation of this probe, solely for $\mathrm{dCO}_{2}$ monitoring, impractical.

Several fiber optic $\mathrm{dCO}_{2}$ probes have been devel oped recently, but few have been commercialized. M ost of these sensors utilize the Severinghaus principle, with a $\mathrm{pH}$ sensitive dye and optical fiber used in place of the $\mathrm{pH}$ electrode. The dye and bicarbonate buffer are contained in the distal end of the fiber, behind the $\mathrm{CO}_{2}$ gas permeable membrane, where the optical fiber detects the relative fluorescence or absorbance of either the protonated, unprotonated, or both forms of the dye.

Although a number of fiber optic probes for $\mathrm{dCO}_{2}$ detection have been developed (14-18), none were intended specifically for fermentation/cell culture applications. In many cases, the sensors had a short lifetime, were sensitive to interfering compounds, and had a restricted range of measurement.

Uttamlal and Walt (19) developed a fiber optic $\mathrm{dCO}_{2}$ sensor using the fluorescent dye hydroxypyrenetrisul- fonate (HPTS) for monitoring $\mathrm{dCO}_{2}$ in fermentations. The advantage of this dye system was that the protonated and unprotonated forms had distinct excitation maxima, allowing a ratiometric measurement of $\mathrm{pH}$ and thus $\mathrm{dCO}_{2}$. The use of a ratiometric method reduces potential error in the output due to photobleaching of the dye, lamp intensity fluctuations, or changes in the dye concentration. Furthermore, the isosbestic point of the dye (i.e., the wavelength at which the relative fluorescence of the two forms of the dye is the same) of $417 \mathrm{~nm}$ may be used to detect sensor drift due to photobleaching. YSI, I nc. has licensed Uttamlal and Walt's technology and has developed and commercialized a fiber optic $\mathrm{dCO}_{2}$ sensor, theYSI 8500 (20). To our knowledge, this is the only available fiber optic, in situ sensor designed for industrial fermentation and cell culture processes.

In this study, we evaluated the YSI 8500 to determine whether it is suitable for continuous in situ monitoring and control of $\mathrm{dCO}_{2}$ in mammalian cell culture processes. The sensor was tested against the fol lowing criteria: (1) adequate response time, sensitivity, and accuracy; (2) a linear range encompassing the operating $\mathrm{dCO}_{2}$ range; (3) minimal effect by physical process parameters $(\mathrm{pH}$ and temperature); (4) minimal interference from medium components (glucose, glutamine, and glutamate) and metabolic wastes (lactate and ammonia); (5) tolerance to clean-in-place (CIP) and SIP processes; (6) adequate robust construction; (7) minimal contamination risk; (8) simple calibration process; and (9) minimal sensor drift. Following evaluation at reactor scal es of $30,40,340$, and $2000 \mathrm{~L}$, we implemented the YSI 8500 in an on-line control strategy in which $\mathrm{dCO}_{2}$ was removed by nitrogen sparging of the culture.

\section{Materials and Methods}

Spinner Flask Experiments. Experiments testing the sensor response time, linearity, sensitivity, and the effects of $\mathrm{pH}$, temperature, metabolic nutrients and wastes, CIP conditions, and SIP conditions were conducted in a $250 \mathrm{~mL}$ spinner flask apparatus. This apparatus had $0.22 \mu \mathrm{m}$ hydrophobic filters for gas supply and exhaust, a magnetic stir bar for agitation, and PHAR-MED L/S 13 tubing for gas sparging (i.d. $=0.8$ $\mathrm{mm}$ ). The spinner flask apparatus was placed in a warm box (Bellco Roll-In Incubator) at $37.0^{\circ} \mathrm{C}$ (unless otherwise specified) and at atmospheric pressure $(\sim 760 \mathrm{mmHg})$. A magnetic stir plate (Thermolyne type 45700 Cellgro stirrer) agitated the spinner flasks at $100 \mathrm{rpm}$. The spinner flasks were filled with $500 \mathrm{~mL}$ of phosphate buffered saline (PBS), pH 6.8, to submerge the YSI 8500 probe.

Prior to the experiments, the YSI 8500 was calibrated between the range of $1 \%$ and $25 \% \mathrm{CO}_{2}$ by sparging a $25 \%$ $\mathrm{CO}_{2} / 75 \% \mathrm{~N}_{2}$ gas mixture until the output stabilized for a minimum of $30 \mathrm{~min}$. YSI 8500 measurements were in units of $\% \mathrm{CO}_{2}$ and taken at 1-min intervals.

The desired $\mathrm{dCO}_{2}$ concentrations were achieved by sparging the spinner flask with gas mixtures of known $\mathrm{CO}_{2}$ concentration from certified $( \pm 0.2 \%)$, pressurized cylinders (Aga Gas) at approximately $100 \mathrm{~cm}^{3} / \mathrm{min}$. For the sensitivity experiment, gases from $5 \%$ and $10 \% \mathrm{CO}_{2}$ pressurized cylinders were mixed by varying the relative flow through rotameters to generate the $5.6 \%$ and $6.2 \%$ $\mathrm{CO}_{2}$ concentrations.

Two off-line bl ood gas analyzers (BGAs) (Ciba Corning 278 model and Chiron Diagnostics 248 model) were used to confirm the $\mathrm{dCO}_{2}$ concentrations. Samples were taken from the spinner flasks for BGA analysis when the output 
of the YSI 8500 had equilibrated for a minimum of 30 min. The BGAs were calibrated in the range of $0-10 \%$ $\mathrm{CO}_{2}$. All experiments were performed in duplicate. $\mathrm{pH}$ measurements were made using a $\mathrm{pH}$ probe (Mettler Toledo type 405) and the BGAs (for pH 6.0-8.0).

The effect of cell culture metabolites experiment used the following chemicals: D-( \pm -glucose (Sigma), L- $( \pm$ )lactic acid (Sigma), ammoni um chloride (Mallinckrodt), $200 \mathrm{mM}$ glutamine (Gibco BRL), and glutamic acid (Sigma). A stir/hot plate (Thermolyne Cimarec 2) was used to heat the spinner flasks to $50{ }^{\circ} \mathrm{C}$ for the effect of CIP experiment.

Cells and Media. A recombinant $\mathrm{CHO}$ cell line, grown on microcarriers in Genzyme's proprietary cell culture medium, was used in this work. I nitially, the cell culture medium contained phenol red. By the end of the process, the phenol red was completely removed.

Bioreactor Cell Culture. The working volumes of the reactors used in this study were $30,40,340$, and $2000 \mathrm{~L}$. Prior to inoculation, the reactors with the probe in place and containing PBS were steam-sterilized at $134{ }^{\circ} \mathrm{C}$ for a minimum of $40 \mathrm{~min}$. The cell culture was operated in a continuous, perfusion mode. Bioreactor pressure was controlled to 3.0 psig. $\mathrm{N}_{2}$ was sparged into the cell culture through a sintered sparge element on a dip tube.

Calibration and Operation of the YSI $\mathbf{8 5 0 0}$. Prior to the SIP process, a new sensor capsule was placed onto the distal end of the $25 \mathrm{~mm}$ probe for the 30, 40, and $2000 \mathrm{~L}$ scales and onto the $19 \mathrm{~mm}$ probe for the $340 \mathrm{~L}$ scale. The probe was inserted into the reactor and sterilized. After the SIP step, the reactor temperature and the agitation rate were controlled to setpoint and the reactor was sparged with a $15 \% \mathrm{CO}_{2} / 85 \% \mathrm{~N}_{2}$ gas mixture. This gas mixture was generated either by using a premixed gas mixture from a pressurized gas cylinder (Aga Gas) or by using the bioreactor's calibrated mass flow controllers (MFC). During the calibration and the cell culture process, the YSI 8500 measured the $\mathrm{dCO}_{2}$ at 1-min intervals in units of $\% \mathrm{CO}_{2}$. The calibration of the YSI 8500 was performed when the output of the YSI 8500 was stable for at least $30 \mathrm{~min}$.

\section{Results and Discussion}

Sensor Response Time. The response time of the probe was tested by removing the probe from a $250 \mathrm{~mL}$ spinner flask equilibrated to $5 \% \mathrm{CO}_{2}$ and quickly inserting it in another spinner flask equilibrated to $10 \% \mathrm{CO}_{2}$. The response time was defined as the time it took for the sensor to reach $90 \%$ of its final $\mathrm{dCO}_{2}$ value $\left(\mathrm{t}_{90 \%}\right)$. The $\mathrm{t}_{90 \%}$ of the $\mathrm{YSI} 8500$ to a change from $5 \%$ to $10 \% \mathrm{CO}_{2}$ was found to be $6 \mathrm{~min}$ (Figure 1 ). This response time is adequate, considering the slow metabolic rates in mammalian cell culture processes.

Linearity and Range. To test the linearity of measurement in the $\mathrm{dCO}_{2}$ range of $0-25 \%$, which encompasses the $\mathrm{pCO}_{2}$ of typical mammalian cell culture processes $\left(100-200 \mathrm{mmHg}\right.$ ), the $\mathrm{dCO}_{2}$ in the spinner flask was increased incrementally from $0 \%$ to $5 \%, 10 \%$, $17 \%$, and then $25 \% \mathrm{CO}_{2}$. The output of the YSI 8500 was linear in this $\mathrm{dCO}_{2}$ range with an $\mathrm{R}^{2}=0.9997$ (Figure 2). BGA measurements were also linear in this range $\left(R^{2}\right.$ $=0.95$ ), despite the instruments having been calibrated in the range of $0-10 \% \mathrm{CO}_{2}$. The maximum $\mathrm{CO}_{2}$ concentration that may be used for the calibration of the BGA 278 model is $12 \%$.

Sensitivity. The sensitivity was defined as the ability of the sensor to detect slight variations in $\mathrm{dCO}_{2}$. To test the sensitivity of measurement, the $\mathrm{dCO}_{2}$ concentration

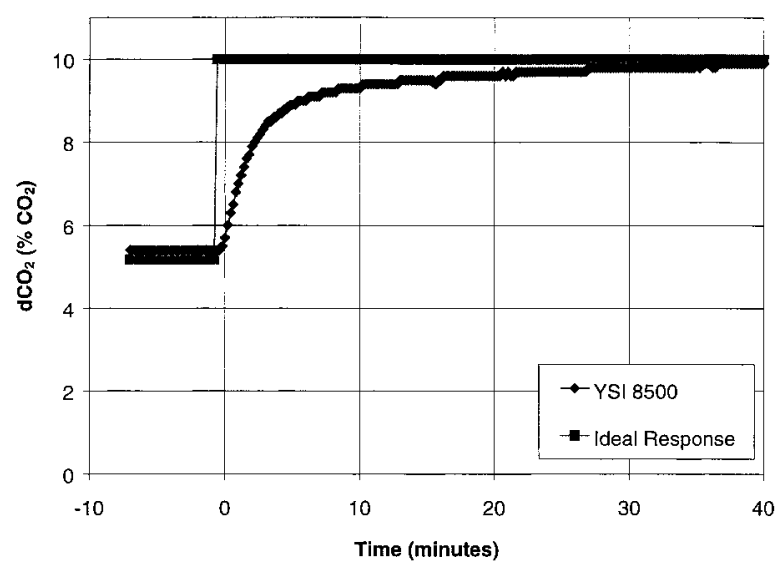

Figure 1. The response time ( t $_{90 \%}$ ) of the YSI 8500 from $5 \%$ to $10 \% \mathrm{CO}_{2}$ at $37.0{ }^{\circ} \mathrm{C}$ in PBS was found to be $6 \mathrm{~min}$.

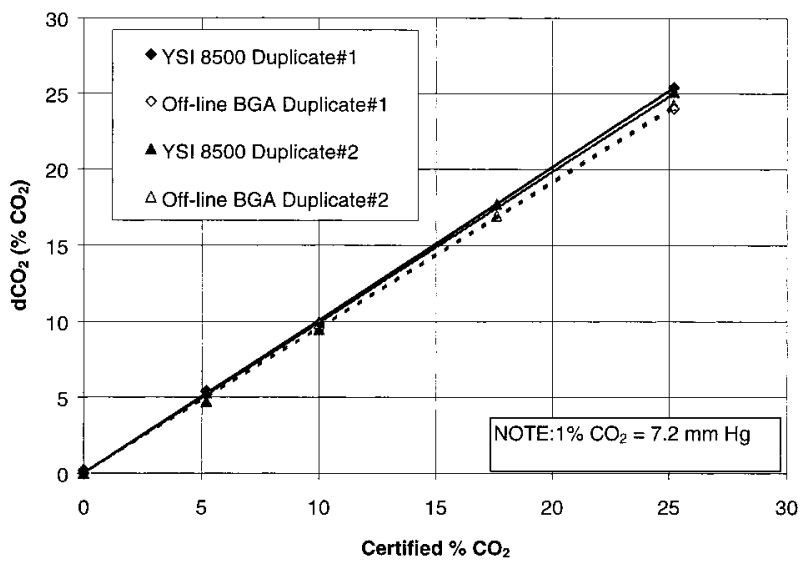

Figure 2. Linearity, from $0 \%$ to $25 \% \mathrm{CO}_{2}$, of the $\mathrm{dCO}_{2}$ output of the $\mathrm{BGA}$ and $\mathrm{YSI} 8500$ at $37^{\circ} \mathrm{C}$. The $\mathrm{dCO}_{2}$ calibration range of the $\mathrm{BGA}$ is $0-10 \% \mathrm{CO}_{2}$. The $\mathrm{dCO}_{2}$ calibration range of the YSI 8500 is $0-25 \% \mathrm{CO}_{2}$.

in the spinner flask was incrementally increased from $5.0 \%$ to $5.6 \%$ and then $6.2 \%$. Both the BGA and the YSI 8500 were able to detect $\mathrm{dCO}_{2}$ changes of approximately $0.5 \% \mathrm{CO}_{2}(\sim 3.6 \mathrm{mmHg})$ (Figure 3).

Effect of $\mathbf{p H}$. Since the output from the YSI 8500 is a function of the $\mathrm{pH}$ in the sensor capsule, it was important to establish the effect of changes in culture $\mathrm{pH}$ on the measured $\mathrm{dCO}_{2}$ values. To test the effects of $\mathrm{pH}$ changes, the PBS contents of the spinner flask, initially lowered to $\mathrm{pH} 2.0$ with $1.0 \mathrm{~N} \mathrm{HCl}$, were incrementally increased to $\mathrm{pH} 8.0$ with $2.0 \mathrm{M} \mathrm{NaOH}$. The $\mathrm{dCO}_{2}$ was maintained at $10 \%$. Under these conditions, $\mathrm{dCO}_{2}$ measurements were found to be unaffected by $\mathrm{pH}$ changes (Figure 4).

Effect of Metabolic Nutrients and Wastes. The interference of common metabolic nutrients and wastes, individually and in combination, on the measured $\mathrm{dCO}_{2}$ output of the YSI 8500 was tested at ranges typical of mammalian cell culture processes: glucose $0-7 \mathrm{~g} / \mathrm{L}$, lactate $0-5 \mathrm{~g} / \mathrm{L}$, glutamine $0-5 \mathrm{mM}$, glutamate $0-5 \mathrm{mM}$, and ammonia 0-5 $\mathrm{mM}$. Desired concentrations were achieved by adding aliquots of concentrated solutions or a measured amount of the chemical to the spinner flask, with the contents of the spinner flask maintained at $10 \%$ $\mathrm{CO}_{2}$. Since none of the metabolites, either individually or a combination of all five compounds, noticeably affected the $\mathrm{dCO}_{2}$ measurement at the upper and lower limits of the test concentration ranges, intermediate concentrations were not tested.

Effect of Clean-in-Place (CIP) and Steam-in-Place (SIP) Processes. U pon termination of most mammalian 


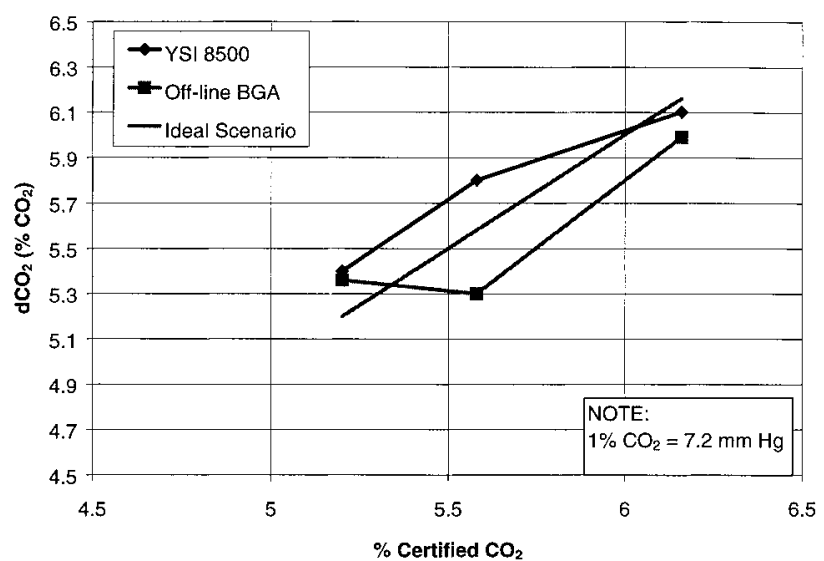

Figure 3. Sensitivity of the $\mathrm{dCO}_{2}$ output of the YSI 8500 and the $B G A$ at $37.0^{\circ} \mathrm{C}$.

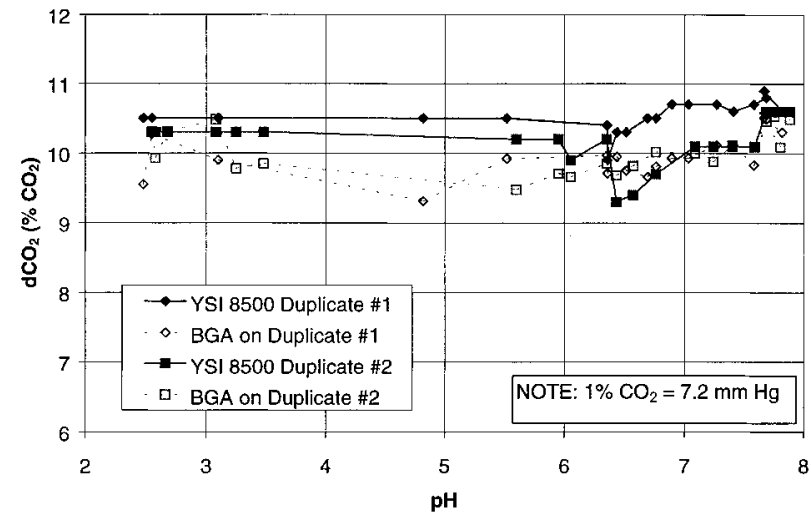

Figure 4. Effect of culture $\mathrm{pH}$ on the $\mathrm{dCO}_{2}$ output of the $\mathrm{YSI}$ 8500 and the BGA at $37.0^{\circ} \mathrm{C}$ in PBS. The $\mathrm{dCO}_{2}\left(10 \% \mathrm{CO}_{2}\right)$ was constant for the duration of the experiment.

cell culture processes, the bioreactor, generally with all in situ probes still inserted in the reactor, undergoes a CIP process. The ability of the sensor capsule to withstand a typical CIP process was tested by exposing the probe to a $0.2 \mathrm{M} \mathrm{KOH}$ solution at $50{ }^{\circ} \mathrm{C}$ for a minimum of $4 \mathrm{~h}$. Prior to the CIP process, the accurate measurement of $\mathrm{dCO}_{2}$ in PBS equilibrated to $10 \% \mathrm{CO}_{2}$ was ensured. The PBS was then removed from the spinner flask and replaced with $0.2 \mathrm{M} \mathrm{KOH}$. After the CIP process and following a triplicate rinse with water-forinjection (WFI), the flask was refilled with $500 \mathrm{~mL}$ of PBS. Measurements taken when the PBS was equilibrated with $10 \% \mathrm{CO}_{2}$ remained accurate, indicating that the sensor was not affected by the CIP process (\% difference pre-CIP $\rightarrow$ post-CIP $=2.5 \%$ ).

The ability of the sensor capsule to withstand the high temperatures of a typical SIP process was investigated during an autoclave cycle of $20 \mathrm{~min}$ at $122{ }^{\circ} \mathrm{C}$. Prior to the SIP process, the accurate measurement of $\mathrm{dCO}_{2}$ in PBS equilibrated to $10 \% \mathrm{CO}_{2}$ was ensured. After the autoclave cycle, the spinner flask was reequilibrated with $10 \% \mathrm{CO}_{2}$ at $37.0^{\circ} \mathrm{C}$. The $\mathrm{dCO}_{2}$ measurements remained accurate, indicating that the sensor was not affected by the SIP process ( $\%$ difference pre-SIP $\rightarrow$ post-SIP $=$ $1.5 \%)$.

Calibration of the YSI $\mathbf{8 5 0 0}$. The calibration period was observed to be approximately $4 \mathrm{~h}$ at the $30 \mathrm{~L}$ scale (Figure 5). The length of the calibration period is primarily a function of the agitation rate, the gas sparge flowrate, and the mass transfer characteristics of the bioreactor (e.g., the bubble size), rather than that of the sensor response. At the $30 \mathrm{~L}$ scale, we did not optimize

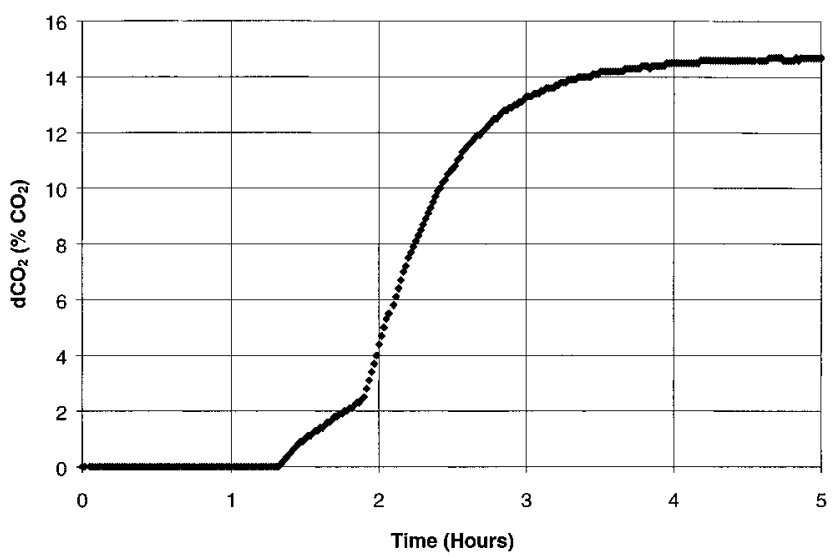

Figure 5. Calibration of the YSI 8500 in a $30 \mathrm{~L}$ reactor at 36.0 ${ }^{\circ} \mathrm{C}$. During the calibration period, a gas mixture of $15 \% \mathrm{CO}_{2}$ was sparged through a sintered tip element at a flowrate of 1 $\mathrm{SL} / \mathrm{min}$ in $\sim 25 \mathrm{~L}$ of PBS. At $4 \mathrm{~h}$, the output of the YSI 8500 had stabilized. At $5 \mathrm{~h}$, the output of the YSI 8500 was set to $15 \%$ from $\sim 15.5 \% \mathrm{CO}_{2}$ (the equilibrated value).

these parameters for minimal calibration time. During the calibration period, a gas mixture of $15 \% \mathrm{CO}_{2}$ was sparged through a sintered tip element at a flowrate of $1 \mathrm{sL} / \mathrm{min}$ into $\sim 25 \mathrm{~L}$ of PBS (initially at a $\mathrm{dCO}_{2}$ of $0 \%$ ). At $5 \mathrm{~h}$ (Figure 5), the output of the YSI 8500 was set to $15 \%$ from $\sim 15.5 \% \mathrm{CO}_{2}$ (the equilibrated value).

The calibration period could be shortened if the probe could be calibrated in an external device of less volume (e.g., the spinner flask apparatus) prior to the SIP process.

Effects of Bioreactor Pressure and Temperature on Measured $\mathbf{d C O}_{2}$. In mammalian cell culture processes, it is conventional practice to quantify $\mathrm{dCO}_{2}$ as an equilibrium gas-phase concentration either as a mole fraction $\left(\mathrm{y}_{\mathrm{CO} 2}\right)$ or as a partial pressure $\left(\mathrm{pCO}_{2}\right)$. The $\mathrm{YSI}$ 8500 currently uses \% gas-phase concentration as the standard unit of measurement to allow for an easy calibration with a gas of known $\mathrm{CO}_{2}$ composition at any given condition. The detrimental effects of el evated dCO concentration to mammalian cell cultures presumably are better correlated with the liquid-phase concentration. If temperature and pressure are kept constant, the gas and liquid-phase concentrations are directly proportional, in which case either may be used to monitor and correlate $\mathrm{dCO}_{2}$ to physiological effects.

In large-scale reactors, the hydrostatic pressure can have a significant effect on the $\mathrm{dCO}_{2}$ (e.g., $1 \mathrm{~m}$ of liquid height above the probe increases the $\mathrm{pCO}_{2}$ by approximately $75 \mathrm{mmHg}$ ). From the literature and our observations, this change can be physiologically significant. Even fluctuations in barometric pressure can change the $\mathrm{pCO}_{2}$ by $\pm 10 \mathrm{mmHg}$.

If temperature is varied during the process, then a true liquid-phase concentration or an "effective gas-phase concentration", corrected to account for differences in solubility, would be more appropriate. With an increase in temperature from 30 to $40{ }^{\circ} \mathrm{C}$, the solubility of $\mathrm{CO}_{2}$ decreases by approximately $25 \%$. This would be equivalent to an increase in "effective" $\mathrm{pCO}_{2}$ from, for example, 100 to $125 \mathrm{mmHg}$ at $37.0^{\circ} \mathrm{C}$ and may be physiologically significant.

The effect of temperature changes on measured $\mathrm{dCO}_{2}$ values was determined by incrementally increasing the temperature of the spinner flask contents from 29.0 to $41.0^{\circ} \mathrm{C}$, while maintaining a constant $\mathrm{dCO}_{2}$ of $10 \%$. The chosen temperature limits encompass the typical range of mammalian cell culture processes. It has been shown 


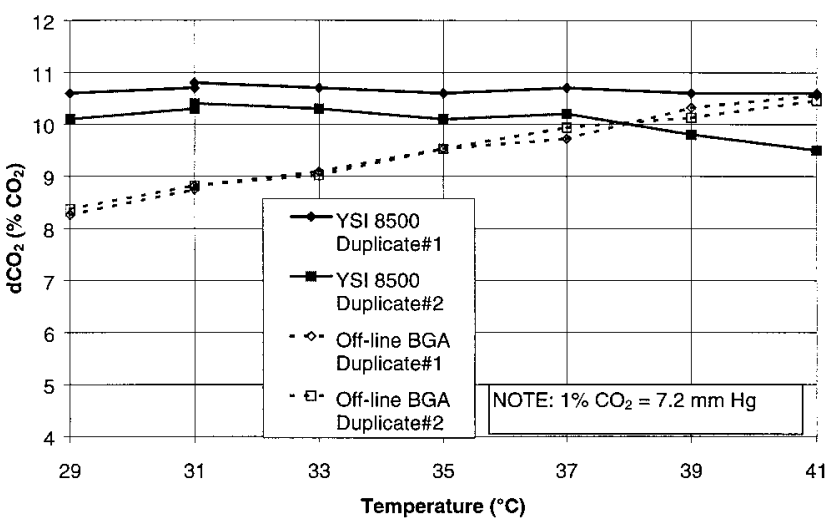

Figure 6. Effect of temperature on the $\mathrm{dCO}_{2}$ output of the $\mathrm{YSI}$ 8500 and the BGA. The $\mathrm{dCO}_{2}$ of the PBS contents was constant for the duration of the experiment at $10 \% \mathrm{CO}_{2}$. The YSI 8500 and the BGA data were temperature-corrected.

that heat shock results in the cessation of cell growth in mammalian cells at temperatures greater than $41^{\circ} \mathrm{C}(21)$ and that the growth of mammalian cells essentially stops at $29^{\circ} \mathrm{C}(22)$.

Since the saturation concentration of dissolved gases is a function of temperature, the YSI 8500 has an internal algorithm to correct measured values at different operating temperatures. This temperature compensation al gorithm was tested and found to be accurate (Figure 6). The BGAs used in this experiment measured the $\mathrm{pCO}_{2}$ at $37.0^{\circ} \mathrm{C}$ and corrected for the temperature of the reactor sample $\left(29-41{ }^{\circ} \mathrm{C}\right)$ using an operator-entered sample temperature and an internal algorithm. However, the corrected values from the BGAs were inaccurate, possibly as a result of an inaccurate algorithm, as compared to those from the YSI 8500 (Figure 6).

Sensor Drift in Long-Term Culture. Since continuous mammalian cell culture processes can be operated over extended periods of time, the output of the YSI 8500 was monitored to determine whether it significantly drifted during the process. The drifting of the output of the YSI 8500 was determined by comparison with the measured value from the BGA, which is less susceptible to drifting since it is calibrated with certified gases every hour. Over the approximate 2-month duration of a cell culture run, there was a relatively constant offset be tween the BGA and the YSI 8500 of $29 \pm 5 \mathrm{mmHg}$ (Figure 7). A constant offset suggests that there was no significant drifting in the YSI 8500 measurements. After a 35-day run at the $40 \mathrm{~L}$ scale, a postrun calibration was performed with $10 \% \mathrm{CO}_{2}(87 \mathrm{mmHg})$; it was found that the sensor had drifted by approximately $10 \mathrm{mmHg}$ over this time period.

The difference between the outputs from the BGA and the YSI 8500 was minimal when both instruments measured $\mathrm{dCO}_{2}$ at atmospheric pressure, in the absence of cells, and at $37.0^{\circ} \mathrm{C}$. The approximately $20-30 \mathrm{mmHg}$ difference between the outputs from the BGA and the YSI 8500 (Figure 7) most likely arose from sample offgassing, which can occur by the change in total pressure (atmospheric, gauge, and hydrostatic head above the probe) from the pressurized bioreactor to the sample bottle at atmospheric pressure. The extent of off-gassing is dependent upon the time period from reactor sampling to actual BGA sample injection for analysis. Other factors that could have led to this measurement discrepancy are heterogeneous mixing between the probe and sample port location and high viable cell concentrations (i.e., cellular respiration may increase the $\mathrm{pCO}_{2}$ in the sample).

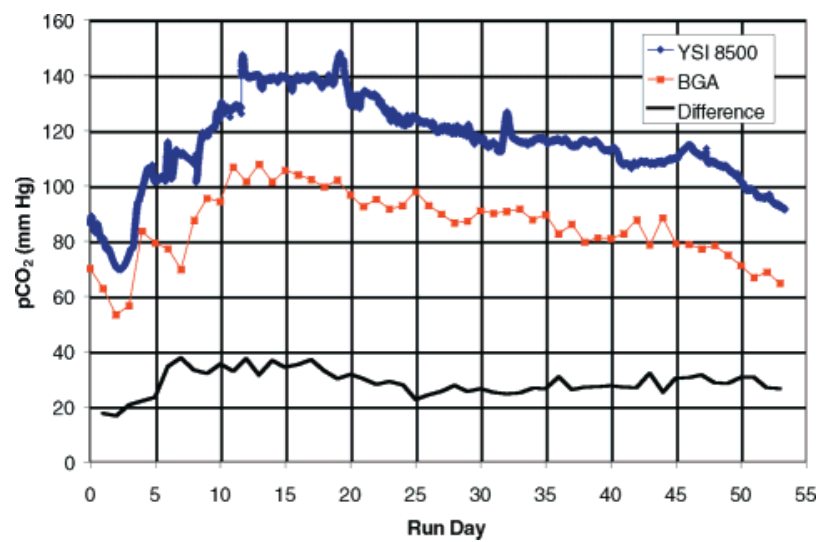

Figure 7. Comparison of the $\mathrm{YSI} 8500$ and $\mathrm{BGA} \mathrm{dCO}_{2}$ measurements in a $340 \mathrm{~L}$ microcarrier-based $\mathrm{CHO}$ cell perfusion process.

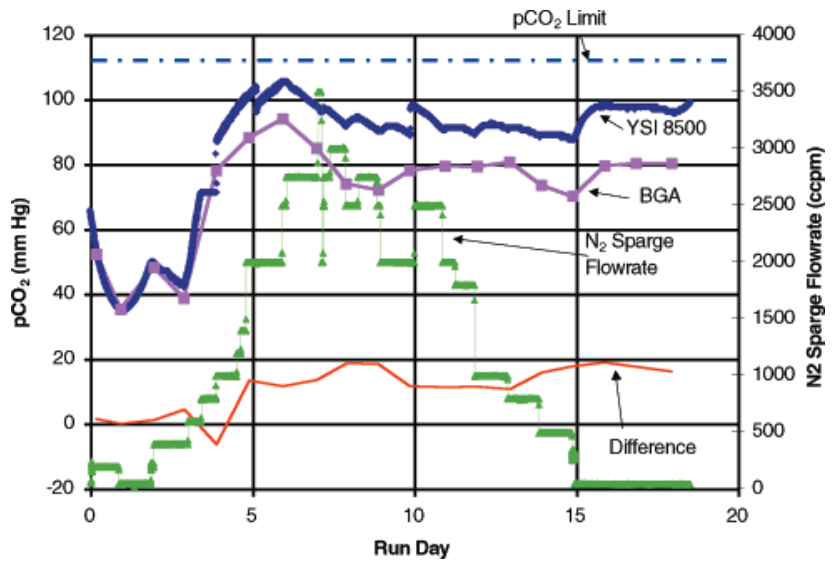

Figure 8. Controlling the $\mathrm{pCO}_{2}$ under a process limit of 110 $\mathrm{mmHg}$ by adjusting the $\mathrm{N}_{2}$ sparge flowrate on the basis of the on-line output from the YSI 8500 in a $2000 \mathrm{~L}$ microcarrier-based $\mathrm{CHO}$ cell perfusion process.

Controlling $\mathbf{d C O}_{2}$ Using $\mathbf{N}_{\mathbf{2}}$ Sparging. Once the reliability of the YSI 8500 had been established, a dCO control strategy was investigated. Using a predetermined upper $\mathrm{pCO}_{2}$ process limit and the on-line output trends from the YSI 8500, the $\mathrm{N}_{2}$ sparge flowrate was increased if the $\mathrm{pCO}_{2}$ was increasing, maintained if the $\mathrm{pCO}_{2}$ was constant, or lowered if the $\mathrm{pCO}_{2}$ was decreasing. The $\mathrm{N}_{2}$ sparge flowrate adjustment could be varied to respond to an increasing/decreasing trend as indicated by the $\mathrm{pCO}_{2}$ probe output. Manual control was monitored every $3 \mathrm{~h}$ to maintain the $\mathrm{dCO}_{2}$ bel ow the upper process limit. Most large scale mammalian cell culture processes operate within the $\mathrm{pCO}_{2}$ range of $150-200 \mathrm{mmHg}$. For the $2000 \mathrm{~L}$ CHO cell microcarrier perfusion process, an upper $\mathrm{pCO}_{2}$ process limit of $110 \mathrm{mmHg}$ was chosen to test the control method (Figure 8). F or this 20 day run, the $\mathrm{dCO}_{2}$ was controlled in the operating range by adjusting the $\mathrm{N}_{2}$ sparge flowrate. This method was successful in maintaining the $\mathrm{pCO}_{2}$ below the upper process limit. Future work will focus on configuring an automatic proportional-integral-derivative (PID) control loop to control the $\mathrm{pCO}_{2}$ to a setpoint. The dissolved oxygen (DO) was maintained at setpoint ( $\pm 1 \%$ air saturation) for the entire duration of this run (results not shown). The DO control mechanism at the $2000 \mathrm{~L}$ scale consisted of in situ DO probes, which were linked to a controller that varied the magnitude of the oxygen sparge flowrate. During periods of increasing $\mathrm{N}_{2}$ sparge flowrate, the DO control compensated for increased $\mathrm{CO}_{2} / \mathrm{O}_{2}$ removal by increasing the $\mathrm{O}_{2}$ sparge flowrate. At no point in this 
experiment was increased foaming due to the $\mathrm{N}_{2}$ sparge flowrate observed.

\section{Conclusions}

The fiber optic based $\mathrm{dCO}_{2}$ sensor, the YSI 8500, was determined to meet all selection criteria for in situ implementation into our bioreactors. The robust construction of this probe posed a minimal risk of process contamination. The response time, $t_{90 \%}$, of $6 \mathrm{~min}$ was adequate for the typical rate of change in the $\mathrm{dCO}_{2}$ of the bioreactor and for on-line control. The range of the sensor was at least $0-180 \mathrm{mmHg}$, which spans most mammalian cell culture $\mathrm{dCO}_{2}$ operating ranges. The output was linear $\left(R^{2}=0.9997\right)$ over this range. Sensitivity of measurement was $0.5 \% \mathrm{CO}_{2}(3.6 \mathrm{mmHg})$. The presence of metabolic wastes (lactate, glutamate, and ammonium) and nutrients (glucose and glutamine) as well as physical process parameters $(\mathrm{pH}$ and temperature) did not interfere with the accurate measurement of $\mathrm{dCO}_{2}$.

There was no significant drift or loss of accuracy due to sensor drifting at reactor scales of 30,40,340, and $2000 \mathrm{~L}$ for a 2-month duration. A constant offset of approximately $20 \mathrm{mmHg}$ was observed between the measurements of the YSI 8500 and the off-line BGA for the entire length of the process. This offset is attributed to bioreactor sample off-gassing prior to BGA analysis; thus, we believe the in situ probe gives a more reliable indication of reactor conditions. The YSI 8500 is amenable to continuous monitoring and feedback control. A $\mathrm{dCO}_{2}$ control strategy, using $\mathrm{N}_{2}$ sparging to maintain the stability of the cell culture at different reactor scales, was demonstrated.

\section{Acknowledgment}

The authors would like to thank the generous support of cell culture personnel at Genzyme's 51 NYA and Allston Landing facilities for operating the YSI 8500 and collecting data from the various reactor scales. We acknowledge Rob Spokane of YSI , Inc. for his invaluable assistance in implementing the YSI 8500 at all cell culture scales within Genzyme Corporation. The authors would like to thank J ack Prior, Richard Schoenfeld, and Claudia Buser for their suggestions during the revision of the manuscript.

\section{References and Notes}

(1) Drapeau, D.; Luan, Y.-T.; Whiteford, J . C.; Lavin, D. P.; Adamson, S. R. Cell Culture ScaleUp in Stirred Tank Reactors. Presented at the Annual Meeting of the Society of Industrial Microbiology, Orlando, FL, 1990.

(2) Aunins, J. G.; Henzler, H.-J. Aeration in Cell Culture Bioreactors. In Bi otechnol ogy: A Multi-Volume Comprehensive Treatise; Stephanopoulos, G., Rehm, H.-J, Reed, G., Puhler, A., Stadler, P. J . W., Eds.; VCH Verlag: Weinheim, Germany, 1993; Vol. 3.

(3) Gray, D.; Chen, S.; Howarth, W.; Inlow, D.; Maiorella, B. $\mathrm{CO}_{2}$ in Large-Scale and High-Density $\mathrm{CHO}$ Cell Perfusion Culture. Cytotechnology 1996, 22, 65-78.
(4) Kimura, R.; Miller, W. Effects of Elevated $\mathrm{pCO}_{2}$ and/or Osmolality on the Growth and Recombinant tPA Production of CHO Cells. Biotechnol. Bioeng. 1996, 52, 152-160.

(5) deZengotita, V.; Kimura, R.; Miller, W. Effects of $\mathrm{CO}_{2}$ and Osmolality on Hybridoma Cells: Growth, Metabolism and Monoclonal Antibody Production. Cytotechnology 1998, 28, 213-227.

(6) Taticek, R.; Petersen, S.; Konstantinov, K.; Naveh, D. Effect of Dissolved Carbon Dioxide and Bicarbonate on Mammalian Cell Metabolism and Recombinant Protein Productivity in High-Density Perfusion Culture. Presented at Cell Culture VI, San Diego, CA, 1998.

(7) Alberts, B.; Bray, D.; Lewis, J .; Raff, M.; Roberts, K.; Watson, . Molecular Biology of theCell; Garland: New York, 1989.

(8) Madshus, I. Regulation of intracellular $\mathrm{pH}$ in eukaryotic cells. Biochem. J . 1988, 250, 1-8.

(9) Thorens, B.; Vassalli, P. Chloroquine and Ammonium Chloride Prevent Terminal Glycosylation of I mmunogl obulins in Plasma Cells without Affecting Secretion. Nature 1986, $321,618-620$.

(10) Kimura, R.; Miller, W. Glycosylation of CHO-Derived Recombinant tPA Produced under Elevated $\mathrm{pCO}_{2}$. Biotechnol . Prog. 1997, 13, 311-317.

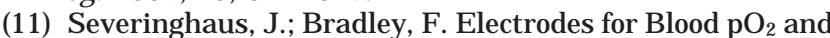
$\mathrm{pCO}_{2}$ Determination. J. Appl. Physiol. 1958, 13, 515-520.

(12) Puhar, E.; Einsels, A.; Buhler, H.; Ingold, W. SteamSterilizable $\mathrm{pCO}_{2}$ Electrode. Biotechnol. Bioeng. 1980, 22, 2411-2416.

(13) Shoda, M.; Ishikawa, Y. Carbon Dioxide Sensor for Fermentation Systems. Biotechnol. Bioeng. 1981, 23, 461-466.

(14) Vurek, G.; Peterson, J.; Goldstein, S.; Severinghaus, J. Fiber-Optic pCO2 Probe. Proc. Fed. Am. Soc. Exp. Biol. 1982, 41(5), 1484.

(15) Zhujun, Z.; Seitz, W. A Carbon Dioxide Sensor Based on Fluorescence. Anal. Chim. Acta 1984, 160, 305-309.

(16) Munkholm, C.; Walt, D. A Fiber Optic Sensor for $\mathrm{CO}_{2}$ Measurement. Talanta 1988, 35(2), 109-112.

(17) Mills, A.; Chang, Q.; McMurray, N. Equilibrium Studies on Colorimetric Plastic Film Sensors for Carbon Dioxide. Anal. Chem. 1992, 64(13), 1383-1389.

(18) Parker, J.; Laksin, O.; Yu, C.; Lau, M.; Klima, S.; Fisher, R.; Scott, I.; Atwater, B. Fiber-Optic Sensors for $\mathrm{pH}$ and Carbon Dioxide Using a Self-Referencing Dye. Anal. Chem. 1993, 65(17), 2329-2334.

(19) Uttamlal, M.; Walt, D. A Fiber-Optic Carbon Dioxide Sensor for Fermentation Monitoring. Biotechnology 1995, 13, 597-601.

(20) Spokane, R.; Pitts, G.; Wu, P.; Cordonnier, M.; Ordaz, D. An Optical Sensor for the in situ Monitoring of Dissolved Carbon Dioxide in Microbial Fermentations. Presented at American Chemical Society National Meeting, Anaheim, CA, 1999.

(21) Tsao, E.; Bohn, M.; Numsuwan, V.; Omstead, D.; Munster, M. Effect of Heat Shock on the Production of Human Erythropoietin from Recombinant $\mathrm{CHO}$ Cells. Biotechnol. Bioeng. 1992, 40, 1190-1196.

(22) Sureshkumar, G.; M utharasan, R. The I nfluence of Temperature on a Mouse- Mouse Hybridoma Growth and Monodonal Antibody Production. Biotechnol. Bioeng. 1991, 34, 101-105.

Accepted for publication J uly 31, 2000.

BP000089C 